\title{
Juzgar a jueces. Discurso normativo regio, control judicial y poder político (Castilla, siglo XV)
}

Judge the Judges. Royal Normative Discourse, Judicial Controlling and Politic Power (Castile, 15th Century)

Elisa Caselli

DOI: https://doi.org/10.24215/23468971e126

Universidad Nacional de San Martin, Argentina

casellidinizo@gmail.com

Recepción: 10 Abril 2020

Aprobación: 10 Mayo 2020

\section{Resumen:}

A partir de considerar la administración de justicia como un acto de gobierno y, por lo tanto, inescindible de las relaciones de poder político, en el presente artículo analizaremos, los dispositivos y discursos destinados a controlar la conducta de los jueces en la Corona de Castilla hacia finales del siglo XV, así como las consecuencias y derivaciones de tales mecanismos. Asimismo, se ponderará hasta qué punto justiciables y pleiteantes se veían afectados por la gestión de los jueces y por los dispositivos implementados para controlarlos.

Palabras clave: Administración de justicia, Poder político, Jueces, Castilla, Siglo XV.

\begin{abstract}
:
In the following paper we analyze the devices to control judges and its consequences in the Crown of Castile in the 15th Century, considering the Administration of Justice as an act of Government, and therefore inseparable from the Political Power. Furthermore, we study how the conduct of the Judges affected the actors involved in the trials.
\end{abstract}

KeYwords: Administration of Justice, Politic Power, Judges, Castile, 15th Century.

\section{INTRODUCCIÓN}

"Nos, deseando dar buena cuenta a Dios nuestro Señor del cargo que de Él tenemos en la tierra e especialmente de la justicia que por Él nos es encomendada; e porque mejor e más prestamente pueda ser administrada, hemos acordado...". ' Con estas palabras, Fernando e Isabel prologaban una serie de ordenanzas destinadas a mejorar, según el propósito declarado, la administración de justicia. Como es sabido, la consideración de ser Vicarios de Dios en la tierra, para impartir justicia en Su nombre, se erigía como la condición clave de la función regia y hacía de la justicia la tarea esencial del gobierno de la monarquía (Garriga, C., 2004, p.17). De allí que la imagen del "rey-juez" se consolidara con mayor fuerza y adquiriera, asimismo, una gran perdurabilidad a lo largo del tiempo. Por la misma razón, desde épocas tempranas, se puso especial cuidado en las «calidades» que debían reunir los oficiales encargados de administrar la justicia ordinaria, vale decir, aquellos que actuarían en nombre del rey. En el ámbito de la Corona de Castilla, el interés de la Monarquía por supervisar la labor de los jueces se hizo perceptible al menos desde el siglo XIII: se regula sobre el tema en el Fuero Real, tomando especial centralidad en las Siete Partidas. Mientras que el Ordenamiento de Alcalá de 1348, promulgado durante el reinado de Alfonso XI, preveía ya la realización de pesquisas con el fin específico de seguir de cerca el comportamiento de los jueces. Con el tiempo, la idea de que el rey debía velar por la correcta administración de justicia se fue afianzando y con ello se perfeccionaron los instrumentos institucionales destinados efectuar ciertos controles (Fortea Pérez, J., 2003, pp.179-180).

Durante el reinado de los Reyes Católicos, período en el cual se circunscribe nuestra investigación, se puso un énfasis particular en implementar medidas tendientes a mejorar el funcionamiento de la justicia e impedir prácticas abusivas por parte de los jueces. En cuanto a los mecanismos de control, se crearon o revitalizaron 
instituciones clave que perdurarían largamente, como las visitas, las pesquisas y los «juicios de residencia». Respecto de estos últimos, si bien se conocían desde el siglo XIII, hasta ese momento su reglamentación había sido menos precisa y su aplicación, más discontinua. Se ha sostenido que el pleno desarrollo de esta institución no se produciría hasta después de la promulgación, en 1500, de los Capitulos para corregidores y jueces de residencia (Fortea Pérez, J., 2003, p.180). No obstante, la documentación estudiada nos permite afirmar que el mecanismo parecía bastante aceitado ya en las últimas décadas del siglo XV, con la particularidad de que al juicio lo incoaba un oficial a tal fin designado: el "juez de residencia”. Mientras se desarrollaba dicho proceso, a través del cual se juzgaba el desempeño del corregidor, cuando el plazo de su cargo tocaba su fin, el juez de residencia asumía de modo formal todas las funciones del corregimiento, hasta el arribo del nuevo juez. Por esta razón, las medidas relativas a corregidores y jueces de residencia comenzaron a emitirse de manera conjunta. Las sentencias pronunciadas en dicho juicio eran elevadas al Consejo Real, donde los corregidores tendrían ocasión de ofrecer sus descargos. Expresada en estos términos, la operación de control y ulterior verificación pareciera sencilla. Sin embargo, tanto durante su desarrollo como en su derrotero posterior, e incluso una vez cerrado el mismo, tenían cabida actuaciones judiciales diversas, que terminaban por complicar de manera considerable los procesos de controles y eventuales puniciones. En efecto, el análisis de la documentación permite apreciar que los pretendidos dispositivos de control podían desembocar en entrecruzamientos verdaderamente farragosos, provocando que su (declarado) propósito principal se diluyera en la nebulosa.

A partir de considerar la administración de justicia como un acto de gobierno - premisa que entendemos sustancial para comprender la dinámica judicial, no solo del período estudiado sino de la sociedad de Antiguo Régimen en general-y, por la misma razón, inescindible de las relaciones de poder político, en las páginas que siguen, analizaremos la intencionalidad de inspección y contralor sobre la conducta de los jueces, expresada en la normativa y la confrontaremos con la complejidad que respecto de las mismas cuestiones exhiben las fuentes judiciales. Para llevar adelante dicha comparación se examinarán, por un lado, textos normativos de origen regio y, por otro, documentación de procedencia judicial (procesos, ejecutorias, notificaciones, etc.), conservada principalmente en dos repositorios: el Archivo General de Simancas (AGS) y el Archivo de la Real Chancillería de Valladolid (ARCHV), circunscribiéndonos al ámbito de la Corona de Castilla, durante el período más arriba indicado. El propósito central del trabajo será ponderar el alcance de los instrumentos de control -a partir de entenderlos en su «naturaleza política»- y su incidencia en la práctica judicial. Para ello cotejaremos los discursos ${ }^{2}$ de las disposiciones -sus usos y destinatarios-con aquellos de las provisiones que ordenaban las pesquisas y, asimismo, con los resultados obtenidos, sus consecuencias y derivaciones, siempre consideradas en el marco de las relaciones de poder político propias del momento. Finalmente, pero no menos importante, se intentará ver hasta qué punto justiciables y pleiteantes se veían afectados por la gestión de los jueces y por los dispositivos implementados para controlarlos, sin desatender las estrategias que los primeros utilizaban para salvaguardarse de los segundos.

\section{PODER POLÍTICO Y NORMATIVA: LA JUSTICIA REAL EN LAS CIUDADES}

“¿Hay Derecho si no hay un poder que imponga lo que los juristas elaboran en su laboratorio sapiencial?” A la pregunta, que formulaba en un sentido casi retórico, el autor respondía con una negación enfática: "el ordo iuris propuesto por teólogos y juristas no es pleno Derecho si no hay quien lo imponga”. Con estas palabras, F. Tomás y Valiente (1996, p.25) ponía en discusión alguna de las afirmaciones vertidas por Paolo Grossi en su libro sobre «El orden jurídico medieval», que él prologaba, señalando que un cuadro que no contemplara la relación fundamental entre poder político y Derecho quedaba incompleto. Si bien este trabajo no se centra en el mismo período, la sentencia del historiador trágicamente desaparecido resulta aquí absolutamente válida. Cuando se pronuncian normas o disposiciones con el propósito manifiesto de incidir con ellas en el orden público es, sin dudas, porque se posee la facultad o la fuerza para imponerlas o, cuanto menos, para luchar 
por su imposición. En otras palabras, la normativa nace siempre en el marco de unas «relaciones de poder», pero, además, y dado que por su propia naturaleza se las pretende vinculantes al conjunto de la comunidad, ese poder adquiere la particular connotación de «político». ${ }^{3}$ En definitiva, las disposiciones con capacidad normativa surgen invariablemente del «poder político», cualquiera sea la forma que este tenga ${ }^{4}$.

En el espacio que nos ocupa, la organización política se había visto marcada, desde los siglos medievales, por la impronta de las sucesivas invasiones musulmanas, que habían alcanzado a dominar casi toda la superficie peninsular, y por las consiguientes luchas que los cristianos emprendieron, con la intención de conquistar dichos territorios. Las guerras, aunque estuvieron lejos de ser permanentes, sumadas a la mayor o menor belicosidad de unas zonas fronterizas siempre móviles, les confirieron unas características particulares a las sociedades que se conformaban, acorde los cristianos avanzaban hacia el sur, ganando terreno al islam. Unas monarquías todavía débiles, una nobleza incipiente y movimientos de población espontáneos fueron los protagonistas de esas nuevas configuraciones políticas.

La organización espacial se fue armando en base a una compleja trama de relaciones en la que sobresalía una monarquía cuya preeminencia ofrecía aún flancos endebles y que, por lo tanto, se veía en la necesidad permanente de ceder espacios jurisdiccionales. Bajo la forma de «privilegio» o «ley privada» (privilegium, privus legis) (Lalinde Abadía, J., 1970, p.180), se fijaban u otorgaban dispensas sobre las costumbres, el uso de la tierra y de los bienes comunales, las cuales, al recibir el reconocimiento real, se elevaban a la condición de «fuero». Estas ratificaciones, con sus reglas, siempre particulares, pasaron a formar parte del orden jurídico territorial. A partir del siglo XIII, en especial bajo los auspicios del rey Alfonso, el Sabio, se produjo un formidable intento de homogeneizar e integrar jurídicamente el reino. No obstante, las jurisdicciones, con sus facultades para dictar normas e impartir justicia, pervivirían aún largo tiempo, ocasionando superposiciones constantes y los consecuentes litigios, más o menos explícitos, en el gobierno y administración de cada uno de esos espacios.

Ciudades, villas, lugares, y otras entidades menores, como aldeas, cotos o granjas, existían tanto bajo jurisdicción directa del monarca, como en ámbitos de jurisdicción señorial, ya fueran laicos o eclesiásticos. Las ciudades de realengo de mayor envergadura funcionaban, con relación a su gobierno y al poder ejercido sobre sus términos, como si se tratara de un espacio señorial más, conservando, al igual que los señoríos, sus capacidades de administrarse, de dictar disposiciones y ordenanzas y, asimismo, de negociar con el monarca, según las circunstancias. Sobre este último punto, cabe recordar las intenciones de los reyes de controlar las instituciones locales, a través de un representante directo suyo. La figura clave en este sentido sería sin dudas la del «corregidor $»^{5}$,denominación inspirada en el principio de «corregir». ${ }^{6}$

A. Bermúdez Aznar (1974, pp.29-30 y 100-101) encuentra un primer antecedente en los veedores y enmendadores alfonsinos, mientras que B. González Alonso (1970, pp.25-27), de acuerdo a las funciones desempeñadas, hallaría un precursor en el "juez de salario", instituido por Sancho IV en las Cortes de 1286 y 1296, o en los "jueces de fuera parte", mencionados durante la minoridad de Alfonso XI. A pesar de la diferencia terminológica, su naturaleza y funciones eran similares: se trataba de jueces enviados por el rey a los municipios, cuyos salarios debían ser asumidos por las ciudades. ${ }^{7}$ Las designaciones de corregidores que dependían directamente del Consejo Real, mediante provisiones emitidas en nombre del rey- no se hicieron desde el comienzo de modo homogéneo para todas las ciudades, sino que variaban de acuerdo a la organización política de cada una de ellas. Durante el reinado de Isabel y Fernando se consolidó la institución del corregimiento (Diago Hernando, M., 2004), instituyéndola como órgano normal de la jurisdicción local ordinaria, con competencias y modalidades de actuación más definidas (Cuartas Rivero, M., 1975, p.259). Los nombramientos se efectuaron con mayor regularidad, siempre bajo la premisa de constituir, desde un punto de vista formal, la presencia del rey en los municipios (Fortea Pérez, J., 1991, p.122). Paralelamente, la resistencia que las ciudades oponían a la recepción de los corregidores tendió a aplacarse y la conflictividad que solía provocar fue disminuyendo (Guerrero Navarrete, Y., 1994, p.107). 
Además de la tarea central de administrar justicia, competían a su cargo diversas funciones de gobierno. ${ }^{8}$ Con respecto a la justicia, asumían la jurisdicción del municipio, con capacidad para conocer en primera instancia y apelaciones, tanto en causas civiles como criminales, quedando los alcaldes ordinarios subordinados a su actuación. Con el fin de proteger su juicio ecuánime, las leyes determinaban que los jueces no debían trabar lazos, ni entablar relaciones personales de ningún tipo en el ámbito de su jurisdicción que pudieran afectar su imparcialidad e independencia. Por la misma razón, se limitaba a un año el ejercicio de estos cargos, vencido dicho plazo, debían ser trasladados. Sin embargo, se han constatado numerosos casos de corregidores que permanecían largos años en un mismo lugar (contrayendo matrimonio, adquiriendo propiedades, etc.). ${ }^{9}$ Por otra parte, debe recordarse que el espacio jurisdiccional de cada corregidor solía cubrir varias ciudades, entre las cuales este alternaba su presencia; durante las semanas o meses que se ausentaba, actuaba en su nombre el "teniente" o "lugarteniente" de corregidor para cuyo nombramiento aquel se hallaba facultado, y no era extraño que designara a un alcalde local, con lo cual la intencionalidad de las disposiciones quedaba, también allí, desvirtuada. Puede decirse sin la mínima duda que los responsables de administrar justicia trababan relaciones de diferentes tipos en su espacio jurisdiccional, haciéndose con ello partícipes activos de alianzas políticas y de redes clientelares. Si bien se trataba de vínculos siempre móviles, en tanto respondían a configuraciones que, por su propia naturaleza, eran cambiantes (Dedieu, J., 2000, pp.24-25), resultaba difícil que el corregidor pudiera escapar al juego faccioso de las rivalidades locales, situación que casi invariablemente lo conducía a asumir compromisos que de una u otra manera podían incidir en sus decisiones judiciales. ${ }^{10}$ Estas apreciaciones nos conducen a un aspecto central del tema aquí tratado: la idoneidad y honestidad de los jueces.

\section{CALIDADES Y REQUISITOS PARA DESEMPEÑAR EL OFICIO DE JUZGAR}

Para poder ejercer como juez había ciertos requisitos básicos que cumplir. ${ }^{11}$ Asimismo, se debía contar preferentemente con una formación académica, aunque, como es sabido, había una proporción considerable de legos e incluso de iletrados entre quienes administraban justicia. A partir de la segunda mitad del siglo XV, comenzaría a preferirse la titulación de letrado y a valorarse la experiencia (Roldán Verdejo, R., 1989, pp. 41-87), a pesar de que los no titulados continuarían desempeñándose durante mucho tiempo. Hacia finales del siglo, el paso por las universidades pasaría a formar parte de la prescriptiva, si bien en la práctica perviviría cierta flexibilidad, por ejemplo, con relación a militares desempeñándose como jueces (Asenjo González, M., 2017, p.98). De todos modos, y aunque subsistiera una gran heterogeneidad en lo que hacía a la aptitud de los jueces, primaba una noción muy extendida respecto a la «calidad» de su persona. A principios del siglo XVI, un procurador lo describía como un oficio "tan noble que pide mucho honor", ${ }^{12}$ pues ejercían tareas de justicia y gobierno como agentes reales. Así, aquellos encargados de impartir la justicia regia debían adornarse de virtudes semejantes a las que debía exhibir el príncipe: rectitud, templanza, modestia y vigilancia (Mantecón Movellán, T., 2002, p.71).

Interesa destacar aquí que estos requerimientos tan elevados habían cobrado forma durante la Baja Edad Media, a partir de dos procesos fundamentales e íntimamente relacionados: por un lado, la consideración, según los teóricos de la época, de que el rey ejercía una justicia que lo volvía "semejante a Dios" (Gauvard, C., 2010, p.896). Por otro, la transformación clave operada en el desarrollo procesal: la preocupación de la Iglesia por extirpar la herejía, con la consiguiente instauración de los primeros tribunales inquisitoriales, condujo a una modificación sustantiva de los procedimientos judiciales no solo en la justicia eclesiástica sino también en la laica, para las cuales aquellos servirían de modelo de referencia (Jacob, R., 2014, p.190). La inquisitio se instalaría, así, como la vía procedimental privilegiada. De la ordalía, como instancia definitoria de culpabilidad, donde se entendía que Dios mismo se hallaba detrás del resultado de la prueba (brasas, agua hirviendo, etc.), se pasó a una instrucción penal que dependería del juez, quien, «bajo juramento», juzgaría 
de acuerdo a su «conciencia». "El juramento de los jueces aparece como el rito por el cual se instaura, en la historia del derecho, la supremacía de la razón sobre el rito” (Jacob, R., 2014, p.272, traducción nuestra). Estos cambios sustanciales: Dios ejecutaría justicia a través de los reyes como Sus Vicarios, que a su vez encomendarían esta tarea principal a sus oficiales, quienes juraban por Dios que juzgarían de acuerdo a su conciencia, condujeron a la consagración de la figura del juez, dándole una centralidad sustantiva y plena en la administración de justicia.

A nuestro juicio, hay otro elemento clave a observar para comprender la consolidación de la figura del juez en este período. Junto a los cambios recién referidos, se debe considerar «la extensión de la pena pecuniaria como expediente sancionatorio». A través de estos procesos, una justicia de inspiración real (y Divina) se impondría sobre venganzas y componendas privadas, expresándose mediante sentencias de punición o perdón (Follain, A., 2002, pp.10-11). En Europa Occidental, la aplicación de penas pecuniarias se originó con el afianzamiento de una justicia pública, que buscaba colocarse por encima de las justicias privadas y controlar las revanchas violentas entre grupos (Toureille, V., 2013, p.158). Con tal propósito y bajo un criterio de proporcionalidad, se reemplazaría la venganza particular por una compensación económica - de allí que las primeras codificaciones penales parecieran un compendio tarifario (Allinne, J., 2001, p.30)- estableciendo equivalencias entre el daño causado y su precio, es decir, se compensaba económicamente para aplacar el deseo de venganza (Toureille, V., 2013, pp.158-161). Cuando los poderes públicos lograron erigirse como administradores de justicia, con capacidad para reprimir el crimen, sus jueces comenzaron a aplicar tales compensaciones como «pena», de la cual una parte se asignaba a las arcas reales como sanción por haber infringido la ley y quebrantado la paz pública, ${ }^{13}$ mientras que otra porción se aplicaba a su oficio, como derecho por su actuación. De allí que, en nuestra opinión, esta facultad acrecentaba el poder y la centralidad del juez en el escenario judicial.

En el caso de Castilla, las penas pecuniarias se aplicaban en partes que variaban proporcionalmente de acuerdo al delito: al fisco o Cámara Real, a la víctima, al acusador o denunciante y al juez actuante. El criterio de ofrecer una porción del castigo económico a los acusadores de un delito, aunque ellos fueran extraños al suceso denunciado, tenía como fin estimular la colaboración con la justicia; mientras que la parte asignada a los jueces buscaba promover el funcionamiento judicial (Alonso Romero, M., 1985, pp.36-38). El problema evidente era que, tanto en un caso como en otro, no podían evitarse las acciones orientadas por especulaciones sobre el beneficio particular que se obtendría al efectuar una denuncia o emitir un fallo judicial. Y es notorio que ello abría las puertas a una infinidad de arbitrariedades.

Los tres aspectos clave que acabamos de sintetizar modificaron sustancialmente el desarrollo procesal, como decíamos, y al mismo tiempo ubicaron al juez como referente esencial de la justicia. Allí anidan, asimismo, cuestiones centrales para el presente análisis: el hecho de que el rey fuera considerado Vicario de Dios en la tierra para impartir justicia en Su nombre ${ }^{14}$ hacía de la justicia el fin principal del gobierno de la monarquía y, por consiguiente, afirmaba la autoridad de los jueces designados por el rey. Obrando bajo juramento y según su conciencia, estos podían presentarse como "la fuente formal del acto de juzgar" (Jacob, R., 2014, p.191). En otras palabras, el oficio del juez adquiría como fin esencial (o razón de ser) nada menos que la "determinación de la justicia" (Garriga, C., 2015, p.79). Ahora bien, una capacidad semejante requería de controles y de verificación. Al organizar el gobierno de la justicia, el rey debía mantener una actitud de constante vigilancia sobre los magistrados que la impartían en su nombre y mostrarse siempre atento al clamor de sus súbditos ante posibles actos de injusticia. Por tales motivos y para "descargo de su conciencia", los monarcas facilitaban los medios para exigir a los jueces que rindieran cuenta de sus actuaciones (Garriga, C., 2015, pp.93-94 y 96). Si el "buen juez" aparecía como la condición sine qua non para la existencia de justicia, las acciones de los malos jueces implicaban su negación y, por ende, un mal gobierno. Por ello, las injusticias no podían pasarse por alto, correspondía que los malos jueces fueran obligados a reparar los daños provocados por una decisión arbitraria, hubiera sido ésta producto de un abuso o de la mera incapacidad. El principal problema radicaba en aquellos jueces que utilizaban su cargo en beneficio propio, convirtiéndose la aplicación 
improcedente de penas pecuniarias en uno los excesos más comunes cometidos en este sentido (Caselli, E., 2016a, 2016b y 2018).

\section{JUZGAR A LOS JUECES: LOS JUICIOS DE RESIDENCIA}

En la Corona de Castilla, el principal dispositivo de control era la pesquisa. En palabras de B. González Alonso (1981, p.146), esta constituía un "medio de fiscalización o control de los oficiales reales castellanos dotado de vida propia, e independiente de la residencia y la visita" [resaltado del autor]. Se trataba de un mecanismo de indagación secreto, que como tal podía conformar una parte esencial del juicio de residencia. La pesquisa se promovía con la finalidad de inquirir la comisión de actos individualizados, llevados a cabo por oficiales reales determinados y concretos. Con frecuencia los pesquisidores se enviaban como consecuencia de alguna queja recibida, aunque no siempre ni necesariamente fuera así, también podía ordenarse por el mero hecho de indagar sobre el gobierno y la justicia en el señorío real, sin que existiera querella previa alguna. Las «visitas», por su parte, se instituyeron para controlar organismos mayores como Audiencias, Chancillerías o Consejos. Mientras que los «juicios de residencia» se incoaban a los oficiales reales en general. Si bien esta institución se mencionaba desde el siglo XIII, su reglamentación era menos precisa y su aplicación más discontinua, conociéndose instrucciones diversas a lo largo del tiempo: Cortes de Valladolid, 1293, de Burgos de 1308; Ordenamiento de Alcalá de 1348 o disposiciones de Enrique III a principios del siglo XV (Fortea Pérez, J., 2003, pp.179-180). En este trabajo, interesan particularmente las residencias efectuadas a jueces, las cuales, y de acuerdo a lo que hemos podido constatar, se ordenaban ya de modo habitual desde las últimas décadas del siglo XV.

Recordemos que en el período que aquí se estudia -a diferencia de lo que ocurriría en siglos posteriores donde el juez entrante juzgaría al saliente- dicho juicio lo incoaba un oficial a tal efecto designado: el «juez de residencia» (aunque es cierto que algunas veces terminaba de hecho reemplazando al corregidor). Resulta importante apuntar que mientras se desarrollaba el proceso y en el tiempo que durara interregno, es decir, hasta el arribo del nuevo corregidor, aquel asumía de modo formal todas las funciones que este desempeñaba (Cuartas Rivero, M., 1975, p.268). En palabras de B. González Alonso (1970, p.101), la condición de juez de residencia conllevaba en sí la de corregidor interino. ${ }^{15}$ Este hecho, en la práctica, generaba determinaciones superpuestas sobre las mismas causas y disputas competenciales, tanto sobre la actividad judicial como la administrativa, provocando serios inconvenientes, de los cuales dan cuenta numerosos reclamos de vecinos, quienes se quejaban de los gastos y dificultades que traía aparejado para las ciudades la presencia simultánea de los dos jueces. ${ }^{16}$ Dicha condición llevó a que las reglas atinentes a ambos cargos se promulgaran de manera conjunta, como en los ya mencionados Capitulos para Corregidores y Jueces de Residencia, del año $1500 .{ }^{17}$ Respecto de esta obra, síntesis clave para analizar la normativa sobre oficios de justicia en este período, cabe aclarar que no se trataba de una elaboración de ese año, sino de la publicación de un compendio de disposiciones que circulaban con bastante anterioridad, tanto en el ámbito judicial como en las instrucciones enviadas a las ciudades (Losa Contreras, C., 2003, pp.237-237; Asenjo González, M., 2017, pp.99-100). Su particularidad estribaba, en cambio, en que se emitían conjuntamente las normas vinculadas a dichos oficios. Al comienzo del texto puede leerse:

“...Nos entendiendo que cumple a nuestro servicio y a descargo de nuestras conciencias, y a buen regimiento y gobernación de las dichas ciudades, villas y lugares, hemos acordado que de aquí adelante, vos los dichos Corregidores y Jueces de Residencia... guardéis y cumpláis y ejecutéis... las Ordenanzas y Capítulos de yuso contenidos y que hagáis juramento en los casos que mandamos se haga..." [resaltado nuestro] (Capítulos para Corregidores y Jueces de Residencia, Archivo General de Simancas, RGS, LEG, 149212, 207)

La cita que acabamos de reproducir, y que forma parte de la introducción con la que Isabel y Fernando presentaban los Capitulos de 1500, nos permite recuperar algunas cuestiones que consideramos centrales 
para nuestra propuesta: en el discurso normativo, la tarea de los jueces, a través de quienes se determinaba la justicia, aparecía como una parte sustancial del buen gobierno. Ellos eran los ejecutores de la justicia real en las villas y ciudades, pero lo hacían bajo un juramento que, al tiempo que los obligaba a asumir la responsabilidad de sus decisiones, descargaba la conciencia real.

A lo largo de ochenta ítems (cincuenta y siete sobre el corregimiento y veintitrés sobre el juicio de residencia), los Capitulos establecían de manera minuciosa obligaciones y procedimientos, como así también, y con un fin claramente preventivo, las sanciones por su incumplimiento. Escapa a los límites de este trabajo ofrecer su descripción completa, por lo que nos limitaremos a mencionar sintéticamente algunos puntos que aquí interesan: no debían hacer confederaciones ni «parcialidades» con regidores, caballeros ni persona alguna de los pueblos de su corregimiento, tampoco comprar propiedades de ningún tipo ni tener relaciones comerciales; ni ellos ni sus alcaldes, alguaciles u otros oficiales podían ser naturales de la tierra donde llevan el cargo; se ordenaba que no recibieran dádiva alguna, aunque fuera pequeña y que no aceptaran ropas ni posadas, salvo por "sus dineros"; que no cobrarían por asesorías ${ }^{18}$ ni vistas de procesos y menos aún por derechos de ejecuciones; que no dispusieran para sí las penas que habían sido aplicadas a la Cámara real, aunque argumentaran que serían para "obras pías" - es habitual hallar este tipo de declaración, que no era sino una excusa para quedarse con dinero perteneciente al fisco-; que no permitirían que se arrendaran alcaldías, alguacilazgos, escribanías, ni ningún oficio; finalmente, en lo que hacía a la administración de las ciudades, entre otras cosas, se les ordenaba que se ocuparan del buen estado de conservación de puentes, calzadas, muros y edificios públicos; que controlaran las rentas y demás ingresos municipales y que comprobaran en qué se gastaban; que guardaran el orden evitando que se cometieran "pecados públicos", haciendo especial referencia a que se castigaran los juegos de azar, las blasfemias y la usura.

Cuando el oficio de corregimiento tocaba a su fin, desde un punto de vista formal, se podía solicitar una prórroga ${ }^{19}$ (para liquidar asuntos pendientes) o la renovación por un nuevo período, ${ }^{20}$ aunque también se han hallado casos en los que el cargo se extendió por varios años. ${ }^{21}$ Sin embargo, lo más frecuente era que se procediera al juicio de residencia. Repasemos brevemente en qué consistía:

En las «provisiones» se ordenaba al juez de residencia acudir a un determinado corregimiento próximo a vencer, asumir en sí las varas de justicia de tal jurisdicción y, "así tomadas", recibir la residencia del corregidor y todos los oficiales a su cargo. En dichos textos se les encomendaba principalmente ver: "cómo han usado y ejercido el dicho oficio de corregimiento y ejecutado la nuestra justicia, especialmente en los pecados públicos e cómo se guardan las leyes" y, por supuesto, informarse "de las penas que el dicho corregidor y sus oficiales hayan condenado, a cualesquier concejos e personas, pertenecientes a la nuestra Cámara e fisco". ${ }^{2}$ Durante los treinta días que oficialmente duraba el proceso -en la práctica solía extenderse mucho másmientras asumía las funciones del corregimiento, el juez de residencia debía controlar la gestión realizada y, al mismo tiempo, recibir las quejas de quienes se hubieran visto perjudicados por las actuaciones de los oficiales salientes. El plural obedece a que, ya fuera conjunta o separadamente, todos los oficiales debían ser residenciados. Sobre cada reclamo recibido, el juez de residencia podía indicar una pesquisa secreta, solicitar pruebas u otras actuaciones, para luego expedirse mediante sentencia. En sus dictámenes, condenaba o absolvía al residenciado respecto de las denuncias o, en caso de desestimarlas, declaraba a dicho oficial por "libre e quito" de la acusación; podía asimismo elevar la queja al tribunal superior sin fallo previo. Es importante aclarar que, con independencia de sanciones económicas y eventuales costas resultantes del proceso, tocaba a los residenciados pagar a los escribanos del juicio -se trataba de cifras atendibles que sin dudas debían ser previstas por los oficiales como parte de la gestión de su cargo. En el Consejo Real, los oficiales residenciados tenían una nueva oportunidad de ofrecer sus descargos y, en base a ellos, los jueces del máximo tribunal pronunciaban su sentencia definitiva, corroborando o revocando los fallos inicialmente dictados por el juez de residencia, en cada uno de sus ítems.

Tal como se ha sintetizado en el párrafo precedente, pareciera que se trataba de una operación relativamente sencilla. Sin embargo, esta solía derivar en un trámite largo y engorroso tanto para los oficiales 
denunciados como para los denunciantes. Era factible que cada juicio de residencia contuviera decenas de reclamos, con sus respectivas sentencias y confirmaciones o rectificaciones, con resoluciones a veces sumamente difíciles de concretizar, entre otras razones, porque transcurrida la residencia, los oficiales ya habían abandonado el lugar donde el juicio se había desarrollado y se encontraban desempeñándose en otro sitio. Por ejemplo, en 1495, el Consejo Real se expidió a favor del bachiller Francisco de Madrigal, quien varios meses antes, en la residencia efectuada por su oficio en Loja, había sido condenado a restituir diversas cantidades de dinero a personas que se habían visto perjudicadas por sus actuaciones: 1.100 maravedíes a Diego de Alcántara, 15 reales a Lope de la Ribera, 5 reales a Pedro Falcón, etc. Los jueces del tribunal regio entendieron que las sentencias pronunciadas en el juicio de residencia habían sido injustas y dispusieron que todas esas personas devolvieran dichas sumas al bachiller. ${ }^{23}$ Resulta difícil imaginar que este haya logrado recuperar el dinero de cada una de esas personas, más aún cuando ya había sido despojado de autoridad en la ciudad y ejercía como corregidor quien le había efectuado la residencia y había dictado las sentencias en su contra.

Pero la complejidad no se limitaba a esa única circunstancia. A la inversa, podía ocurrir que los afectados por los fallos de un corregidor, habiendo obtenido una sentencia favorable tanto en la residencia como en el Consejo Real, no lograran alcanzar el resarcimiento económico correspondiente. O bien que los juicios de residencia fueran utilizados como una herramienta más en la lucha entre los poderes locales o, también, que, dependiendo de las vinculaciones del residenciado, el trámite cayera en letra muerta. Veamos algunos ejemplos más.

\section{DERIVACIONES Y DERROTEROS DE ALGUNOS JUICIOS DE RESIDENCIA}

* Gutierre de Guanzo, corregidor de Aguilar de Campoo, había sido condenado por el juez de residencia a compensar a Juan Gutiérrez de Villa con 6.500 maravedíes por haberlo tenido preso injustamente. ${ }^{24}$ Sin embargo, Guanzo se negaba a pagar. Gutiérrez, cuya condición social se describía en la causa como de "pobre”, le solicitó al juez que procediera sobre los bienes del corregidor o sobre sus fiadores - no sobra recordar que todos los oficiales antes de asumir un cargo debían, indefectiblemente, ofrecer fiadores capaces de responder por sus actos en caso de que ellos no lo hicieran. Según se desprende del proceso iniciado luego ante la Real Audiencia, Guanzo no disponía de bienes en esa jurisdicción -lo cual es lógico e iría en coincidencia con lo que marcaba la ley- y sus fiadores al parecer no respondieron por él o resultaron insolventes, por lo que Gutiérrez reclamaba al juez de residencia que extendiera la actuación al Valle de Toranzo, donde Guanzo era vecino y poseía bienes, a lo que el magistrado respondió que no se hallaba facultado, ni tampoco tenía salario para eso, ambas cosas ciertas. Guanzo propuso entonces supeditar el caso a la resolución de dos jueces árbitros, ${ }^{25}$ cuya propuesta consistió en que Juan Gutiérrez aceptara tres fanegas de trigo, ${ }^{26}$ a cambio de las cuales le entregaría la sentencia (único documento que él poseía, capaz de hacer valer sus derechos) y se diera por satisfecho. Desconforme con este acuerdo, que con toda razón consideró abusivo, Gutiérrez se presentó en apelación ante los oidores de la Real Audiencia y Chancillería de Valladolid. Allí Guanzo argumentó que existía un compromiso refrendado ante jueces árbitros, que debía ser respetado. No obstante, los oidores dieron por válido el reclamo presentado por Gutiérrez y ratificaron la sentencia dada por el juez de residencia. La ejecutoria, al haber sido emitida por la Real Audiencia, alcanzaba a todas las ciudades, villas y lugares del reino (comprendiendo por ende a la Villa de Toranzo), lo cual no garantiza que el pobre Gutiérrez haya conseguido que el corregidor pagara por el agravio cometido. 
* En 1493, Juan de Burgos fue enviado a la ciudad de Jaén para hacer la residencia a Juan de Torquemada, "teniente de corregidor" -el titular del corregimiento era Alonso Enríquez-, el resultado del juicio se tradujo en un rosario de denuncias de notoria gravedad casi todas ellas, mencionemos algunas: había exigido a un vecino que le pagase para que "le fuese favorable en un pleito que traía ante él"; a otro, fanegas de trigo y cebada para que "le excusase de ir a la guerra"; a un preso, tres castellanos oro para "aliviar su condena"; al arrendador de las penas ${ }^{27}$ de los dados, una licencia para poder jugar naipes y dados en su casa; y lo más grave, tomó para sí penas pecuniarias que había aplicado y cuyo destino debía haber sido la Cámara real. Las sentencias condenatorias del juez de residencia fueron ratificadas en su totalidad por los jueces del Consejo Real, quienes, en nombre de los reyes, sentenciaron a Juan de Torquemada a destierro e inhabilitación perpetuos, aclarando que no solo se le prohibía el desempeño de cualquier oficio público, sino que si era encontrado "en nuestros reinos que muera por ello". ${ }^{28}$

* La residencia del bachiller Ortuño de Aguirre, corregidor de Alcaraz, ofrece otro sin fin de reclamos, pero a diferencia del caso anterior, en casi ninguno de ellos se proporcionan los nombres de los agraviados. Se trataba de demandas generales, sobre delitos o faltas que coincidirían con prácticamente la totalidad de ítems de los Capitulos. ${ }^{29}$ En otras palabras, se lo acusaba de haber infringido casi todas las disposiciones: se había quedado con parte de la recaudación de alcabalas; había retenido para sí derechos por talas y cortes de los propios de la ciudad; no pagaba el censo de la casa en que vivía; por su negligencia, la ciudad había gastado dinero de más; había provocado la pérdida de la renta de las alcabalas de la carne; tenía oficiales que eran naturales de la ciudad; dejaba el corregimiento, sin atender las causas pendientes, para percibir derechos (asesorías) y juzgar en otros lugares; consentía que juegos de azar por dinero, oro y plata, incluso en su propia casa; recibía "dádivas e presentes de muchas personas"; deshonraba y agraviaba a quienes acudían a él en busca de justicia, “diciéndoles palabras injuriosas e echándolos en la cárcel e después en el cepo" y, finalmente, algo que no podía faltar: "hacía bando e partido con muchas personas" ${ }^{30} \mathrm{El}$ juez de residencia pronunció sentencias condenatorias o absolutorias- en varias de las denuncias, desestimando aquellas que no ofrecían precisiones ni nombres que permitieran individualizar los hechos. No obstante, los jueces del Consejo Real revocaron las pocas condenas que contra el corregidor había dictado el juez de residencia, absolviéndolo y dándolo por "libre e quito" de cualquier acusación, exigiendo, además que le fueran abonadas las costas y se le restituyese todo aquello que el juez de residencia le hubiera condenado a pagar.

* En 1490, se ordenó la residencia de Juan de Robles, corregidor de la ciudad de Jerez de la Frontera, y de sus oficiales. En el procedimiento, el juez encontró culpable de varios delitos a Pedro de Castilla, aguacil, a quien condenó en la suma de cincuenta mil maravedíes, para compensar a las numerosas personas damnificadas. ${ }^{31}$ Ante este resultado, desde el Consejo Real se le encomendó a García de la Villa, alcalde mayor de dicha ciudad, a que averiguara lo sucedido, que citara a las mencionadas personas y "oídas las partes solamente sabida la verdad lo más bienmente y sin dilación" les hiciera "cumplimiento de justicia”. En otras palabras, se indicaba una especie de pesquisa sobre la residencia. Cabe apuntar que en este documento los jueces del alto tribunal regio se referían a Pedro de Castilla como "del nuestro Consejo". ${ }^{32}$ A principios del año siguiente, febrero de 1491, lo encontramos actuando ya como corregidor de la ciudad de Toledo. ${ }^{33}$ Tres años más tarde, en 1494, se dispuso que se le hiciera residencia, ${ }^{34}$ de cuyo resultado no hemos hallado noticias y unos meses después, en enero de 1495 , se le otorgaba una prórroga por un año, ${ }^{35}$ a la que se le sumarían otras nuevas en $1499^{36}$ y $1500 .{ }^{37}$ Como habrá advertido el lector, lejos de la movilidad que las leyes disponían 
para el cargo (para que los jueces no "raigasen" ni establecieran vínculos en el lugar donde ejercían su oficio), Pedro de Castilla disfrutó de largos años al frente del corregimiento de una de las ciudades más importantes del reino. Pero hay algo más, indagando sobre las rendiciones de penas a la Cámara real, en los registros de la Hacienda Real, hemos encontrado que, entre los años 1497 y 1501, este juez figuraba entre quienes prestaban dinero a los reyes. En efecto, diversos movimientos anotados por Alonso de Morales, tesorero de lo extraordinario, reflejan préstamos y devoluciones a "Pedro de Castilla, corregidor de Toledo" ${ }^{38}$ El criterio para seleccionar los casos que acabamos de resumir ha sido el de privilegiar aquellos que, por una razón u otra, resultaran válidos para ejemplificar algunas de las consecuencias o derivaciones a las que podía conducir el control de la administración de justicia. Tal complejidad radicaba no solo en la cantidad de demandas que concentraba cada residencia, las cuales según lo resuelto (ratificaciones o rectificaciones) podían dar lugar a nuevas reclamaciones con sucesivas apelaciones, sino (especialmente) en la necesidad por parte de los jueces de proseguir esas disputas que afectaban su imagen ${ }^{39}$ y con ella la posibilidad de continuar desempeñando oficios de justicia, y sobre todo su economía. Como muy bien ha señalado C. Garriga (2015, p.94), en el juez convergían dos personas, una pública, que ejercía la jurisdicción, y otra privada, que debía responder de manera privada por los daños causados en el desarrollo de la actividad pública. En otro lugar (Caselli, E., 2016b), hemos analizado pormenorizadamente de qué manera los jueces gestionaban y defendían, de modo particular, los recursos obtenidos a través de la administración de justicia, pasando de jueces a pleiteantes, muchas veces en el marco de una misma causa judicial. El estudio sobre los juicios de residencia, además de permitirnos completar lo que allí sosteníamos, ilustra con mayor amplitud la complejidad de la práctica judicial del período.

Juan de Torquemada, desterrado e inhabilitado en 1493 tras el juicio de residencia, había sido enviado en 1490 a realizar la residencia al corregidor de entonces, ${ }^{40}$ mientras que Juan de Burgos, luego de las sentencias lapidarias que dio sobre el primero, prolongó su oficio en Jaén y, un tiempo más tarde, en el Consejo Real se recibían críticas sobre su conducta similares a aquellas expresadas contra Juan de Torquemada. ${ }^{41}$ Lejos de constituir una excepción, era habitual que los jueces de residencia permanecieran en los lugares más allá del tiempo indicado en la provisión, en tanto tales o a veces como corregidores. Porque, en realidad, y es un punto que debe destacarse, se trataba de los mismos magistrados que en unas ocasiones actuaban uno, dos o más años como corregidores y, en otras, como jueces de residencia, por uno o más meses. Es decir, aunque no fuera homogénea ni continua en el conjunto de las ciudades, existía una circulación de oficiales. Esta movilidad, si bien moderada (recordemos que las normas indicaban un año en cada lugar), agregaba una complicación más a la dinámica judicial. Pues, al momento de dejar el lugar donde se habían desempeñado, los jueces se preocupaban por cobrar sus derechos pendientes ${ }^{42}$ y reclamar por ellos en caso de conflictos con otros agentes -disputas originadas por lo general a raíz de superposiciones competenciales- y, al mismo tiempo, debían enfrentarse a las probables quejas y acusaciones que pudieran surgir del juicio de residencia. Por tal motivo decíamos que el análisis de estos últimos amplía y enriquece un panorama judicial de por sí complejo.

Como hemos podido constatar (Caselli, E., 2016a, 2016b, 2017, 2018), esta capacidad de los jueces de «gestionar» los réditos de su oficio; es decir, de obtener derechos, aranceles y, en especial, penas pecuniarias a partir de su actividad judicial y de defenderlos, reclamar y eventualmente pleitear por ellos, afectaba de un modo directo a justiciables y pleiteantes -siendo las confiscaciones y los remates de bienes indebidos, con alteraciones procesales, los más comunes y la tortura para obtener una confesión que obrase como prueba para sentenciar una confiscación y el dictado de la pena capital, con el mismo fin, los más graves y flagrantes. Sin embargo, quienes se veían perjudicados por tales abusos hacían oír sus reclamos y, siempre en la medida de sus posibilidades, elevaban sus quejas. Más allá de que alcanzaran o no un resarcimiento por el daño sufrido (que a veces era irreparable, como la ejecución de un familiar ${ }^{43}$ o, por ejemplo, la pérdida de un brazo por culpa de los tormentos recibidos $\left.{ }^{44}\right)$, lo intentaban; los afectados por el mal proceder de un juez presentaban sus demandas, tanto en el marco de los juicios de residencia como por fuera de ellos. Es sumamente habitual 
encontrar denuncias realizadas en instancias de apelación sobre el juez actuante en primera instancia, o bien en causas especialmente incoadas o contenidas en los juicios de residencia que venimos analizando. «Y todo esto hacía también a la cotidianidad judicial». Hemos visto el caso de Juan de Gutiérrez, que en su condición de "pobre" recurrió a la Real Audiencia (si se justificaba tal calidad, se podía acceder al alto tribunal y ser defendido por un abogado de los estrados), sabiendo que solo una sentencia pronunciada por los oidores podía permitirle alcanzar justicia en la ciudad donde residía el corregidor que había procedido injustamente con él y se negaba a pagar una suma por resarcimiento. Vale decir que justiciables y pleiteantes ensayaban, asimismo, sus propias estrategias defensivas.

Pero hay otras cuestiones a destacar de los ejemplos utilizados. La retahíla de reclamos contra el desempeño de Ortuño de Aguirre, de orden genérico y sin ofrecer mayores especificaciones, obliga a pensar en enfrentamientos locales, de los que el corregidor no pudo o no quiso escapar, viéndose de ese modo involucrado en luchas banderizas y asumiendo, muy probablemente, posiciones que incidirían en sus decisiones judiciales y, por ende, políticas. La absolución completa que obtuvo como sentencia firme por parte del Consejo Real puede ser leída entonces como una extensión de las vinculaciones que ciertos grupos de poder locales tenían en el entorno real. Por su parte, las acusaciones efectuadas por el bando opuesto asumían para sí el mismo discurso normativo, con la intención de hacerlo jugar en su favor. Si en este ejemplo los lazos políticos con el ámbito monárquico parecían depender de alguna facción local, en el caso de Pedro de Castilla, nacían de las relaciones estrechas que el propio corregidor había establecido en el más alto nivel de Hacienda regia. El ejemplo ilustra bien una de las formas de acceso a un oficio público, en esta ocasión nada menos que como acreedor de los reyes, otorgándole al mismo un tinte típicamente patrimonial, del que la pervivencia en el cargo y la casi total ausencia de controles se alzan como los rasgos más evidentes. No hace falta preguntarse por el destino de las denuncias que, eventualmente, hubieran podido producirse.

\section{A MODO DE CONCLUSIÓN: CONTROLES Y PODER POLÍTICO}

P. Ponce Leiva (2018, p.348) señala con acierto que analizar los mecanismos de control sobre la "corrupción" en la Monarquía Hispánica en términos de "eficacia" o simplemente bajo el binomio «impunidad de los delitos / debilidad de los castigos», resulta de una cierta estrechez de miras. ${ }^{45}$ En efecto y desde nuestra perspectiva, los dispositivos de control, como visitas, pesquisas y juicios de residencia, tendientes impedir y castigar los abusos y extralimitaciones cometidos por los magistrados, deben ser examinados bajo una premisa que entendemos sustantiva: «la administración de justicia considerada como una tarea más de gobierno». Por lo tanto, las decisiones adoptadas tanto en el terreno de la normativa como en la cotidianidad de la práctica judicial entraban de lleno en la dinámica del poder político. Si la monarquía enviaba corregidores a las ciudades, en tanto representantes suyos, para controlar e intervenir en el gobierno municipal, tenía simultáneamente que verificar que ese oficial que actuaba en su nombre no ofendiera la imagen real y, en consecuencia, tampoco afectara lo que se entendía como «buen gobierno» (aspecto fundamental). No menos importante era ofrecerles a los poderes locales la posibilidad de canalizar su disconformidad ante actuaciones que consideraran abusivas. En otras palabras, tanto los intentos de control establecidos por la monarquía, como las gestiones -públicas y particulares- que los jueces hacían de su oficio o las estrategias de los pleiteantes y justiciables «se conjugaban invariablemente en las relaciones de poder político». Entendemos que descuidar este aspecto sustantivo podría conducir a interpretaciones erróneas o cuanto menos anacrónicas.

No debe olvidarse que la autoridad expresada en el discurso normativo regio hallaba su fundamentación máxima en la voluntad de Dios, mientras que los jueces hacían reposar la suya en una designación real (e indirectamente también divina) y avalaban su proceder jurando por Dios que obrarían de acuerdo con su conciencia. Como hemos visto, a partir de tales concepciones, la figura del juez adquirió predominancia y centralidad en el escenario judicial, como agente capaz de «determinar» la justicia (Garriga, C., 2015, p.79). 
Tales facultades se verían acrecentadas gracias a otro de los cambios procedimentales clave operados desde de los siglos bajomedievales: la extensión de la pena pecuniaria como expediente sancionatorio por excelencia, quedando su aplicación en manos de los magistrados. Si la designación regia, para realizar tareas de justicia y gobierno, enaltecía el oficio, otorgándole además de autoridad, honor y prestigio, la posibilidad de percibir derechos y una porción de las penas pecuniarias incrementaba su incentivo económico. La reputación del cargo se conjugaba en «todas» estas variables, no solo porque lo hacían más atractivo, sino porque inspiraban temor y ampliaban su potencial negociador. No obstante, por elevadas que resultaran sus capacidades, los magistrados debían hacerlas prevalecer en el desempeño cotidiano de su oficio, para cuyo cometido no había más alternativa que medirlas, cotejar fuerzas y «negociar» con los poderes locales. En efecto, para poder desarrollar su tarea gubernativa, de administración y control de recursos, mantenimiento del orden público e impartición de justicia, los corregidores se veían con frecuencia condicionados por los grupos dominantes a nivel local, hecho que los hacía entrar indefectiblemente en las disputas políticas. Los controles establecidos para evitar o, en su caso, condenar las arbitrariedades cometidas por los magistrados deben por ende considerarse como un instrumento más del juego político, no privativo de la monarquía, ni tampoco unidireccional desde esta hacia sus oficiales. Por el contrario, era una herramienta de la que podían valerse, de acuerdo a sus capacidades, los diversos agentes comprendidos en el escenario judicial. En este sentido, el discurso de la normativa, «constitutivo» de una teoría jurídica, devenía en «constituyente» de prácticas políticas. No se trata de una contradicción, ni de un desfasaje entre teoría y práctica, sino de una dinámica particular, propia del poder político de Antiguo Régimen, donde controlar y juzgar a los jueces hacía a la (para nosotros compleja) cotidianidad judicial.

\section{ReFERENCIAS}

Allinne, J. (2001). “Les victimes : des oubliées de l'histoire du droit ?”. En Cario, R. et Salas, D. (dirs.), CEuvre de justice et victimes. Vol. 1 (pp. 25-58). Paris: L'Harmattan.

Alonso Romero, M. (1985). "Aproximación al estudio de las penas pecuniarias en Castilla (siglos XIII-XVIII)". Anuario de Historia del Derecho español, 55, 9-94.

Asenjo González, M. (2017). "El corregidor en la ciudad. La gestión de su oficio y la construcción del habitus, a fines del siglo XV y principios del XVI”. Studia Histórica. Historia Moderna, 39(1), 89-124. Recuperado de: http://r evistas.usal.es/index.php/Studia_Historica/article/view/shhmo201739189124/16935

Balandier, G. (1969). Antropología politica, Barcelona: Edicions 62.

Barriera, D. (2002). "Por el camino de la historia política: hacia una historia política configuracional". Secuencia, 53 , mayo-agosto, 163-196. Recuperado de: http://secuencia.mora.edu.mx/index.php/Secuencia/article/view/779/ 690

Bermúdez Aznar, A. (1974). El Corregidor en Castilla durante la Baja Edad Media (1348-1474). Nogués-Murcia: Universidad de Murcia.

Billoré, M., Mathieu, I. et Avignon, C. (2012). La justice dans la France Médiévale (VIIIe-XVe siècle). Paris: Armand Colin.

Bonachía Hernando, J. (1998-99). "Materiales para el estudio del régimen de corregidores (Burgos 1458-1465)”. Cuadernos de Historia de España, LXXV, 135-160.

Calsamiglia Blancafort, H. y Tusón Valls, A. (2001). Las cosas del decir. Manual de análisis del discurso, Barcelona: Ariel.

Caselli, E. (2019) "Justicia y penas pecuniarias. La gestión del cargo de corregidor y su incidencia judicial durante el reinado de los Reyes Católicos", Magallánica. Revista de Historia Moderna, 6(11), pp. 318-350. Recuperado de: https://fh.mdp.edu.ar/revistas/index.php/magallanica/article/view/3905

Caselli, E. (2018). "Medrar con el suplicio: la tortura judicial como recurso económico en el ámbito jurisdiccional de la Corona de Castilla (siglos XV-XVI)". Clio \& Crimen. Revista del Centro de Historia del Crimen de Durango, 
15, 2018, 63-82. Recuperado de: http://www.durango-udala.net/portalDurango/RecursosWeb/DOCUMEN TOS/1/1_11995_3.pdf

Caselli, E. (2017). "El antijudaísmo en la práctica judicial ordinaria. El caso de un corregidor castellano de finales del siglo XV". Espacio, Tiempo y Forma. III. Historia Medieval, 30, 221-245. Recuperado de: http://revistas.uned. es/index.php/ETFIII/article/view/17239/15767

Caselli, E. (2016a). "Rendering Justice and Administering the Office: Judges and Judicial Officers in Castile during the Reign of the Catholic Monarchs”. En Garavaglia, J. C. - Lamouroux, C. and Braddick, M. (eds.) Serve the Power(s), serve the State. America and Eurasia (Xth-XXth Centuries) (pp. 1-40). Newcastle upon Tyne: Cambridge Scholars Publishing.

Caselli, E. (2016b). "Vivir de la justicia. Los réditos del oficio de juzgar y su incidencia en las disputas jurisdiccionales (Castilla en la temprana Edad Moderna)". En Caselli, E. (coord.) Justicias, agentes y jurisdicciones. De la Monarquia Hispánica a los Estados Nacionales (España y América, siglos XVI-XIX) (pp. 161-195). Madrid: Fondo de Cultura Económica.

Coromines, J. (2012). Diccionario etimológico de la lengua castellana. Madrid: Gredos.

Cuartas Rivero, M. (1975). “Los Corregidores de Asturias en la época de los Reyes Católicos (1474-1504)”, Asturiensia medievalia, 2, 259-278

De Andrés Díaz, R. (2004). El último decenio del reinado de Isabel I a través de la tesorería de Alonso de Morales (1495-1504), Valladolid: Universidad de Valladolid.

Dedieu, J. (2000). “Procesos y redes. La historia de las instituciones administrativas de la época moderna, hoy”. En Castellano, J. et al. La pluma, la mitra y la espada. Estudios de Historia Institucional en la Edad Moderna (pp.24-25). Madrid: Marcial Pons.

Diago Hernando, M. (2004). "El papel de los corregidores en los conflictos políticos en las ciudades castellanas a comienzos del siglo XVI”. En la España Medieval, 27, 195-223. Recuperado de: https://revistas.ucm.es/index.p $\mathrm{hp} / \mathrm{ELEM} /$ article/view/ELEM0404110195A/21998

Follain, A. (2002). "Justice seigneuriale, justice royale et régulation sociale du XVe au XVIIIe siècle: rapport de synthèse”. En Brizay, F. et al. Les justice de Village. Administration et justice locales de la fin du Moyen Âge à la Révolution (pp. 9-58). Rennes: Presses Universitaires de Rennes.

Fortea Pérez, J. (2003). “Quis custodit custodes? Los corregidores de Castilla y sus residencias (1558-1658)”. En Bennassar, B. et al. Vivir el Siglo de Oro. Poder, cultura e historia en la Época Moderna. Estudios en homenaje al profesor Ángel Rodriguez Sánchez (pp. 179-222). Salamanca: Universidad de Salamanca.

Fortea Pérez, J. (1991) "Poder real y poder municipal en Castilla en el siglo XVI". En Pastor, R. et al. Estructuras y formas del poder en la historia (pp. 117-142). Salamanca: Universidad de Salamanca.

Garriga, C. (2015). "Iudex perfectus. Ordre traditionnel et justice de juges dans l'Europe du ius commune. (Couronne de Castille, XVe XVIIIe siècle)". En Dikè. Groupe de recherche sur les cultures juridiques en Europe, Histoire des justices en Europe. 1-Valeurs, représentations, symboles (pp. 79-99). Toulouse : Université de Toulouse.

Garriga, C. (2004). “Orden jurídico y poder político en el Antiguo Régimen”. Istor, 16, 13-44. Recuperado de: http: //www.istor.cide.edu/archivos/num_16/dossier1.pdf

Gauvard, C. (2010). "De grace especial". Crime, État et société en France à la fin du Moyen Age, Paris: Publications de la Sorbonne.

Gómez González, I. (2018). “Corrupción moral versus corrupción profesional: percepción, persecución y castigo en el Antiguo Régimen”. En Andújar Castillo, F. y Ponce Leiva, P. Debates sobre la corrupción en el Mundo Ibérico, siglos XVI-XVIII (pp. 103-114). Biblioteca Virtual Miguel de Cervantes.

Gómez González, I. (2016). “«En defensa de los ministros afligidos de Su Majestad». Las alegaciones jurídicas (porcones) en favor de los jueces del Antiguo Régimen». En Caselli, E. (coord.) Justicias, agentes y jurisdicciones. De la Monarquia Hispánica a los Estados Nacionales (España y América, siglos XVI-XIX) (pp. 197-218). Madrid: Fondo de Cultura Económica.

González Alonso, B. (1981). Sobre el Estado y la Administración de la Corona de Castilla en el Antiguo Régimen. Madrid: Siglo XXI. 
González Alonso, B. (1970). El corregidor castellano (1348-1808). Madrid: Instituto de Estudios Administrativos.

Guerrero Navarrete, Y. (1994-1995). "La política de nombramiento de Corregidores en el siglo XV entre la estrategia regia y la oposición ciudadana". Anales de la Universidad de Alicante. Historia medieval, 10, 99-124. Recuperado de : https://rua.ua.es/dspace/bitstream/10045/6921/1/HM_10_07.pdf

Jacob, R. (2014). La grâce des juges. L'institution judiciaire et le sacréen Occident, Paris: Presses Universitaires de France.

Jara Fuente, J. (2017). “Entre el conflicto y la cooperación: la ciudad castellana y los corregidores, praxis de una relación política hasta la monarquía isabelina”. Studia Histórica. Historia Moderna, 39(1), 53-87. Recuperado de: http:/ /revistas.usal.es/index.php/Studia_Historica/article/view/shhmo20173915387/16934

Lalinde Abadía, J. (1970). Iniciación histórica al derecho español, Barcelona: Ariel.

Losa Contreras, C. (2003). "Un manuscrito inédito de los capítulos de Corregidores enviado al Concejo de Murcia”. Cuadernos de Historia del Derecho, 10, 235-255. Recuperado de: https://revistas.ucm.es/index.php/CUHD/ar ticle/view/CUHD0303110235A/19923

Mantecon Movellán, T. (2002) “El mal uso de la justicia en la Castilla del siglo XVII”. En Fortea Pérez, J., Gelabert, J.y Mantecon Movellán, T. (eds.) Furor et rabies. Violencia, conflicto y marginación en la Edad Moderna (pp. 47-98). Santander: Universidad de Cantabria.

Ponce Leiva, P. (2018). "Mecanismos de control de la corrupción en la Monarquía Hispánica y su discutida eficacia”. En Andújar Castillo, F. y Ponce Leiva, P. Debates sobre la corrupción en el Mundo Ibérico, siglos XVI-XVIII (pp. 341-352). Biblioteca Virtual Miguel de Cervantes.

Roldán Verdejo, R. (1989). Los jueces de la Monarquía Absoluta, Tenerife: Universidad de La Laguna.

Tomás y valiente, F. (1996). "Prólogo" a Grossi, P. El orden jurídico Medieval (pp. 17-26). Madrid: Marcial Pons.

Toureille, V. (2013). Crime et châtiment au Moyen Âge, Ve-XVe siècle, Paris: Seuil.

\section{Notas}

1 El fragmento está extractado de la compilación realizada en 1503 por el licenciado Juan Ramírez, escribano del Consejo, edición facsimilar de 1973: Libro de las Bulas y Pragmáticas de los Reyes Católicos. Instituto de España: Madrid. El subrayado me pertenece. Resulta pertinente aclarar que todas las citas son trasladas al castellano actual, pero respetando rigurosamente su literalidad

2 Si bien nuestro trabajo no discurrirá en torno al análisis del discurso, consideramos oportuno aclarar que entendemos el discurso como una práctica social relacional. Se trata de una relación dialéctica entre un evento discursivo particular y la situación o contexto que lo configura y donde cada una de las partes da forma a la otra. En otras palabras, el discurso es socialmente «constitutivo y constituyente». Seguimos en este planteamiento a Calsamiglia y Tusón, 2001.

3 Estas definiciones, aunque muy escuetas, responden a una visión antropológica de las relaciones políticas. Una síntesis, ya clásica, sobre antropología política puede leerse en: G. Balandier, 1969. Sobre la relación interdisciplinar entre la denominada "nueva historia política" y las ciencias sociales a lo largo de la segunda mitad del siglo XX, en: D. Barriera, 2002.

4 Decimos esto en obvia referencia a la debatida cuestión de la existencia, para este período, de un "estado" como entidad autónoma e impersonal. No nos resulta posible detenernos en estas discusiones, que además escapan a los límites de este trabajo, de todos modos, consideramos oportuno señalar que, en España, un estado con tales características -y al que entendemos como una forma específica más de organización política (Balandier, G. 1969, p.150)- se conformaría recién a lo largo del siglo XIX (e incluso con grandes salvedades). La bibliografía al respecto es muy amplia, pero vale mencionar, entre otros, los trabajos que sobre este tema han realizado: Bartolomé Clavero, António M. Hespanha, Jean-Frédéric Schaub, Carlos Garriga, Francisco Andújar y Xavier Gil Pujol.

5 Como es sabido, son incontables los trabajos dedicados a la figura del corregidor. Solo a título de ejemplo, mencionaremos algunos autores que se han ocupado del tema: B. González Alonso, A. Bermúdez Aznar, M. Lunenfeld, A. Matilla Tascón, Y. Guerrero Navarrete, J. Bonachía Hernando, J. Ruiz Povedano, C. Losa Contreras, M. Diago Hernando, J. Fortea Pérez, M. Asenjo González, J. Jara Fuente, P. Lorenzo Cadarso.

6 Sebastián de Covarrubias, en su Tesoro de la Lengua Castellana (1611), hace derivar un concepto del otro, asociando corregir al cargo: "Corregir: vale enmendar... Corregir, castigar... Corregidor, el que rige y gobierna una ciudad o pueblo. Latine pretor. Corregimiento, cargo de corregidor”. El vocablo «corregidor» proviene del latín corrigere (Coromines, 2012, p.152) y del principio romano ius corrigendi, que remitían a la noción de corregir o enmendar. El concepto se 
habría desarrollado dando lugar en diferentes épocas y espacios a los cargos de: "corrector", "reformador", "reformateur", "corregedor" y "corregidor".

7 A lo largo del siglo XIV -en Cortes de 1349, 1371, 1380 y 1385- se fue perfilando la figura de los jueces de salario, fijándose la anualidad para el ejercicio del cargo (1371), exigiéndose la condición de "hombre bueno", "abonado" y "no poderoso" (1380) y, determinándose la condición de oficio no delegable (1385). El término "corregidor", como oficial real designado para desempeñar tareas de gobierno y justicia en los municipios, fue empleado por primera vez en las Cortes de 1348 (González Alonso, B., 1970, p.33). A partir de allí, el cargo se iría definiendo con mayor precisión y su presencia, extendiéndose a casi todas las ciudades castellanas.

8 Entre otras: convocar y presidir los ayuntamientos (con voto en caso de empate entre regidores); verificar el cumplimiento de las ordenanzas, enmendar o realizar nuevas; preservar el orden público $y$, por supuesto, perseguir los delitos; disponer la custodia de puertos y aduanas que hubiera en su corregimiento y la vigilancia en campos, caminos, ventas y bodegas; fiscalizar la hacienda municipal (tratando de evitar las apetencias de particulares), controlando las rentas concejiles y los gastos efectuados en obras públicas; procurar el abastecimiento de la ciudad y supervisar los precios (Losa Contreras, C., 2003, p.236).

9 Vid infra. Otros casos, asimismo, en: M. Diago Hernando, 2004; Caselli, E., 2016b.

10 Como señala M. Diago Hernando (2004, p.206), los corregidores casi nunca lograron "actuar como un poder moderador capaz de imponer soluciones conciliadoras a las facciones enfrentadas en cada ciudad, sino que, por el contrario, gobernaron con el exclusivo apoyo de una de dichas facciones en detrimento de los intereses de la contraria, a la que sólo le quedó abierto el camino del recurso a las instituciones centrales de gobierno y administración de justicia de la monarquía."

11 Se contemplaban exigencias físicas: la ceguera, la sordera o la insania mental, entre otras, eran impedimentos para el acceso a estos cargos; éticas: en las Siete Partidas se requería que "sean leales e de buena fama e sin mala codicia e que tengan sabiduría para juzgar los pleitos derechamente [...] e buena palabra e sobre todo que teman a Dios..." [Partida III, Título IV, Ley III]; y sociales: por supuesto, ser buen cristiano, a lo que más tarde se sumará la limpieza de sangre -por lo tanto, excomulgados, conversos o sospechados de cualquier herejía quedaban formalmente excluidos-. Asimismo, los afectados a la servidumbre o aquellos que desempeñaban oficios viles, se hallaban impedidos de ejercer el oficio de juzgar. Del mismo modo, las mujeres, salvo las reinas, las duquesas o las herederas de algún señorío [Partida III, Título IV, Ley IV]. En todos los casos, las referencias a esta obra corresponden a la edición: Las Siete Partidas del Rey don Alfonso el Sabio, Imprenta Real, Madrid, 1807.

12 AGS. Consejo Real de Castilla, 1515/16-23-7

13 Varios autores coinciden en describir procesos similares en diferentes espacios: Billoré, M., Mathieu, I. y Avignon, C., 2012, pp.165-166; Toureille, V., 2013, pp.161-162; Allinne, J., 2001, pp.31-32; Alonso Romero, M., 1985. p.13.

14 "Vicarios de Dios son los reyes cada uno en su regno puesto sobre las gentes para mantenerlas en justicia". Partida II, Título I, Ley V.

15 Esto se diferenciaba del "juez pesquisidor", que realizaba una indagación especial, encomendada por lo general a raíz de una denuncia, pues este juez tenía expresamente vedado asumir las funciones de aquel a quien estaba investigando: Cortes de los Antiguos Reinos de León y de Castilla, Tomo IV, Real Academia de la Historia, Establecimiento Tipográfico de los Sucesores de Rivadeneyra, imprenta de la Real Casa, Madrid, 1882. Cortes de Toledo de 1480, Ítem 59.

16 Tales reclamos conducirían a que los juicios de residencia comenzaran a ser incoados directamente por parte del corregidor entrante sobre el saliente, como apuntamos más arriba, práctica que se confirmaría mediante un decreto de 1648 (Fortea Pérez, J., 2003, p.189).

17 Incluidos en el Libro de las Bulas y Pragmáticas de los Reyes Católicos, ya citado. Asimismo, se hallan reproducidos en B. González Alonso, 1970, pp.99-317).

$18 \mathrm{La}$ asesoría, como el nombre lo indica, refería a derechos que los letrados cobraban por asesorar a jueces legos, en especial a la hora de emitir sus fallos. En toda la normativa se estipulaba que los jueces que percibían un salario tenían terminantemente prohibido brindar asesorías y cobrar por ellas.

19 Por ejemplo en: AGS. RGS. 1487.10.241

20 Por ejemplo en: AGS. RGS. 1497.03.215

21 Por ejemplo: el caso de Pedro de Castilla, que aquí analizamos o el de Alonso Ramírez de Villaescusa, quien actuó como corregidor de Valladolid por espacio de ocho años (Caselli, E., 2016b, pp.186-188).

22 AGS. RGS. 1490.02 .290

23 AGS. RGS. 1495.09.44

24 ARCHV. Registro de Ejecutorias [RE] 1500.153.40

25 Debe señalarse que es muy común encontrarse con este tipo de intervenciones, los jueces árbitros o jueces componedores, como también se los denominaba, con mucha frecuencia lograban la resolución de conflictos. Claro que las referencias halladas en apelaciones, como en este caso, nos remiten a una composición que había fracasado. 
26 Como es sabido, los precios del trigo fluctuaban de manera considerable de acuerdo a los años, pero como para ofrecer un marco de referencia al lector, podemos citar un pleito de 1489 (once años antes), donde la fanega de trigo se estimaba en 70 maravedíes aproximadamente [ARCHV. RE. 1489.24.21], mientras que en otro litigio, que duró varios años (1486-1496), el precio de trigo oscilaba entre los 60 y los 130 maravedíes [ARCHV. Pleitos Civiles. Fernando Alonso (F), 1135-1].

27 En otro lugar (Caselli, E., 2019), hemos analizado con detenimiento las penas pecuniarias, en especial aquellas aplicadas a la Cámara real o fisco, mostrando su utilización arbitraria por parte de los jueces y las resistencias para enviarlas al "Tesorero de lo extraordinario", asimismo, hemos mencionado su consideración como renta extraordinaria, entregándolas, en ocasiones, como merced o en arriendos.

28 AGS. RGS. 1493.04.150. Llama la atención la rigurosidad de la pena, cuando en casos más flagrantes que hemos tenido oportunidad de analizar, como torturas o sentencias a muerte, ordenadas con el fin de apropiarse de las penas pecuniarias, apenas si fueron sancionados o directamente no recibieron castigo alguno (Caselli, E., 2017 y 2018).

29 Una vez más, nos permite ratificar lo señalado más arriba: el caso es de 1499 y los demandantes hacían referencia permanente a que el corregidor había infringido los "Capítulos", citando frases casi textuales de los que se publicarían en 1500. Es decir, estas disposiciones circulaban desde antes en diversos ámbitos institucionales.

30 AGS. RGS. 1499.08 .38

31 AGS. RGS. 1490.03 .195

32 AGS. RGS. 1490.03.195

33 AGS. RGS. 1491.02.157. Se trata del primero de una serie de documentos que dan cuenta de sus actuaciones como corregidor en la ciudad de Toledo.

34 AGS. RGS. 1494.10.324

35 AGS. RGS. 1495.01.32

36 AGS. RGS. 1499.12 .08

37 AGS. RGS. 1500.10 .386

38 Documentos reproducidos en R. De Andrés Díaz, 2004.

39 Inés Gómez ha analizado muy bien y desde distintas aristas la defensa que los jueces hacían tanto de su imagen como de la calidad en tanto magistrados (Gómez, I., 2016 y 2018).

40 AGS.RGS. 1490.02.290

41 AGS.RGS. 1492.07.104

42 Nos referimos a aranceles por actos procesales, porciones de penas pecuniarias u otros derechos que por sus actuaciones les correspondieran y que no hubiesen sido liquidados cuando vencía el plazo de su oficio de corregimiento. Hemos analizado estas cuestiones clave y su incidencia en la práctica judicial en: E. Caselli (2019).

43 Por ejemplo en: ARCHV. RE. 1486.4.29; AGS. RGS. 1485.07.171

44 Por ejemplo en: ARCHV. RE. 1496.102.15

$45 \mathrm{La}$ autora propone establecer una distancia entre los fines explícitos y los implícitos de los mecanismos de control, leyéndolos a la luz de dualidades que conducirían a un análisis más enriquecedor que el mero par delito/castigo. Así, los objetivos podrían medirse en términos de: prevención y castigo; negociación e imposición; obtención de información sobre las prácticas y pretensión de gobernar desde las disposiciones; y donde cada medida podría ser estudiada desde estas perspectivas duales (Ponce Leiva, P., 2018, pp.348-349).

\section{BY-NC-SA}

